\title{
Las entidades públicas en Colombia y los procesos de cooperación internacional: un análisis comparado de las experiencias del Servicio Nacional de Aprendizaje (SENA) Public entities in Colombia and their international cooperation processes: a compared analysis of the National Education Service Institution experiences
}

\author{
Rubeny Senior' \& Victor Cera²
}

\begin{abstract}
Copyright: $\odot 2020$
Revista Internacional de Cooperación y Desarrollo.

Esta revista proporciona acceso abierto a todos sus contenidos bajo los términos de la licencia creative commons AtribuciónNoComercial-SinDerivar 4.o Internacional (CC BY-NC-ND 4.0)

Tipo de artículo: Resultado de Investigación

Recibido: septiembre de 2020

Revisado: octubre de 2020

Aceptado: noviembre de 2020

Autores

1 Profesional en Relaciones Internacionales, magister en Cooperación Internacional para el Desarrollo. Proactiva y responsable. Amplia experiencia en investigación del sector de las relaciones internacionales, identificación de factores de riesgo, trabajo en equipo, manejo de presupuestos e identificación de oportunidades para el desarrollo. Experiencia en el sector público y organismos internacionales.

Correo eléctrónico: rubeny.senior@cancilleria.gov.co

rsenior@colombiaun.org

ORCID: 0000-0002-6216-5906

2 Economista; magíster en cooperación internacional para el desarrollo; especialista en formulación y evaluación de proyectos de inversión pública y privada; especialista en informática y telemática, Altamente Emprendedor corporativo con amplia experiencia en la Identificación, Formulación, Evaluación y Dirección de Proyectos Productivos que mejoran el Emprendimiento y la Empleabilidad de la población Rural y/o Vulnerable.

Correo electrónico: vices@misena.edu.co

ORCID: 0000-0002-2894-5095
\end{abstract}

\section{Cómo citar:}

Senior, R. \& Cera, V. (2020). Las entidades públicas en Colombia y los procesos de cooperación internacional: un análisis comparado de las experiencias del Servicio Nacional de Aprendizaje (SENA). Revista Internacional de Cooperación y Desarrollo. 7(2). 119-138

DOI $10.21500 / 23825014.5043$

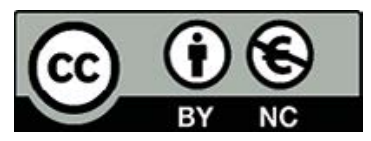

\section{Resumen}

El presente artículo analiza los principales procesos internos y que se desarrollan en las entidades estatales en Colombia. Para ello se tomó el caso del centro de formación para el trabajo Servicio Nacional Enseñanza y Aprendizaje (SENA) a partir del análisis comparado de sus experiencias en Cooperación Internacional con sus pares SENAI en Brasil a nivel Sur-Sur y Mashav en Israel, a nivel Norte-Sur. Los hallazgos evidencian resultados positivos en la transferencia de conocimientos y experiencias en doble vía, receptor y donante, lo que puede ser replicable en una mayor dimensión en el SENA e incluso en otros tipos de entidades pública demostrando la fortaleza de la institución como oferente y receptor de cooperación en Colombia.

Palabras Claves: Cooperación Internacional; Cooperación Norte-Sur; Cooperación Sur-Sur; SENA; organización gubernamental.

\section{Abstract}

This article sets out a research on the main variations among the process of international cooperation inside the state institutions in Colombia. The study takes the national learning service SENA (for its acronym in Spanish) as one of the key institutions in the evolution of international cooperation in Colombia. One of the main objectives is to identify the different ways the institution organizes and exercises internal and external international cooperation processes. To achieve this goal the comparative case method was applied to detect the patterns of the roll the countries play, the types of cooperation, the final effects and how can this be extended throughout the institution. The cases selected were the cooperation projects with Mashav of Israel as North-South Cooperation and Brazil as South-South Cooperation. The results will point out the similarities and strengthens of SENA as a cooperation actor in Colombia and how its experience can be applied in other institutions.

Keywords: International cooperation; North-South Cooperation; South-South Cooperation; SENA; government organization. 


\section{Introducción}

Thomas Piketty, en su libro el "Capital en el siglo xxi" resalta que la difusión de conocimiento y habilidades es una de las claves para el crecimiento de la productividad en una nación (2014, p. 21). El desenvolvimiento de los procesos de Cooperación Internacional (de ahora en adelante $\mathrm{Cl}$ ) en Colombia ha sido distinto con cada país o entidad internacional. Sin embargo, podemos notar un comportamiento marcado en el intercambio de conocimiento como herramienta de $\mathrm{Cl}$ en sus modalidades Norte-Sur (CNS) y Sur-Sur (CSS).

El Servicio Nacional de Aprendizaje (SENA) es una entidad que históricamente ha tenido un papel significativo en el desarrollo económico y social del país, así como en el apoyo que presta en los procesos de cooperación de la política exterior colombiana. La obtención de conocimiento por distintos medios se ha convertido en un objetivo fundamental de todos los países que aspiran a aumentar su crecimiento económico, por lo que se hace necesario profundizar en su análisis para comprender más a fondo el panorama actual de la $\mathrm{Cl}$ en Colombia y el funcionamiento del proceso de cooperación internacional en la práctica con las entidades públicas, particularmente el Servicio Nacional de Aprendizaje.

\section{Cooperación internacional Norte-Sur - Cooperación Vertical}

La forma de relación tradicional entre un país donante y un país receptor, donde existe una verticalidad en la forma en que se toman las decisiones y manejan los procesos en los convenios de cooperación, se ha denominado $\mathrm{Cl}$ Norte-Sur o Cooperación Vertical. Todo esto producto de la asimetría de poder existente entre el país que dona el dinero y el que lo recibe. Este proceso de donación ha recibido el nombre técnico de Ayuda oficial al desarrollo (Hynes \& Scott, 2013).
Los orígenes de este modelo se remontan al escenario posterior a la segunda guerra mundial, donde se volvió necesaria la búsqueda de una estrategia para acelerar el proceso de recuperación de los países que habían quedado devastados por el conflicto, especialmente Europa. Estados Unidos como la potencia económica con menor daño recibido durante el conflicto y con los recursos para iniciar el proceso creó el Plan Marshall, mediante el cual se le envió dinero a Europa para que iniciaran su recuperación económica. Claro está, que, con el avance de la Unión Soviética como alternativa de poder en un mundo bipolar, el plan tenía un fuerte componente político, como señala Duarte y González (2014), no solo fue ayuda humanitaria también fue un instrumento diplomático (p. 124). Adicional a esto, uno de los momentos clave fue en 1961 cuando se creó el Comité de Asistencia para el Desarrollo, en la OCDE, que busca aunar esfuerzos para ayudar a los países menos desarrollados a lograr el desarrollo (Hynes \& Scott, 2013, p. 3).

Ya en la década de los 70, la cooperación se encontró en un escenario aún más favorable para su esparcimiento. La globalización de la economía trajo consigo un fortalecimiento de las relaciones diplomáticas de distintos países, este período se vio caracterizado por un aumento en los recursos destinados a la ayuda oficial para el desarrollo y por el sostenimiento de un paradigma de verticalidad de la ayuda enviada por los países más industrializados (Duarte y González, 2014, p.126).

Durante las décadas de los 80 y 90 , el desgaste de los países donantes al no ver un significativo avance en los indicadores de desarrollo de los países emergentes, sumado a la caída de la Unión Soviética, una de las razones ideológicas para el mantenimiento de la ayuda oficial en términos políticos, provocó una reducción paulatina de los recursos en ciertos países. 
Esto se tradujo en que al iniciar el siglo xxI, la agenda del Comité de Asistencia para el Desarrollo, se consolidó alrededor de los Objetivos de Desarrollo del Milenio (ODM), enfocados especialmente a la reducción de la pobreza y el hambre, con el propósito de poder armonizar las acciones a nivel global (Tezanos y Martínez, 2010, p. 33).

\section{Cooperación internacional Sur-Sur o Cooperación Horizontal}

La Unidad Especial de Cooperación Sur-Sur (CSS) del Programa de las Naciones Unidas para el Desarrollo (PNUD) define la CSS como "un proceso por el cual dos o más países en desarrollo adquieren capacidades individuales o colectivas a través de intercambios cooperativos en conocimiento, recursos y knowhow tecnológico" (citado por Ayllón, 2009, p. 1). Sin embargo, no hay una definición única o universalmente admitida.

Considerando lo anterior, Ayllón (2009) amplía la descripción del contenido de la CSS relacionándolo con un marco de colaboración que "incluye elementos del clásico concepto de Ayuda Oficial al Desarrollo (AOD) pero que va más allá, al abarcar campos como la cooperación política, el comercio, las inversiones o la ayuda financiera, en algunos casos" (p. 2). Con base en ello es necesario mencionar que la CSS está abierta al intercambio en una amplia variedad de campos que competen a los intereses de los países en desarrollo.

Es importante, además, considerar con la debida relevancia la dimensión política que da lugar a la CSS, ya que sus objetivos fundamentales son (al menos en teoría) el fortalecimiento de las relacionesy la promoción de coaliciones que incrementen el poder de negociación de los países en desarrollo (Ayllón, 2009; Lechini; 2009; SECIB, 2009). En su estudio Cronología e historia de la Cooperación Sur-Sur, López (2014) realiza un recorrido en el que compila un total de
295 eventos que a su entender definen lo más relevante de la agenda internacional en CSS en las últimas décadas, sobre todo a partir del año 2000 en el que se acentuó el incremento, pues en sólo tres años de la segunda década del siglo XXI (2010, 2011 y 2012) se pasó de 83 a 114 casos registrados. Para López (2014), el término de CSS estuvo precedido en sus albores por el de Cooperación Técnica entre Países en Desarrollo (CTPD) y relacionado con el concepto homólogo de Cooperación Económica entre Países en Desarrollo (CEPD), y considera que bajo la creciente influencia de los espacios (foros internacionales, bilaterales, regionales) se han producido los más notables aportes al desarrollo conceptual y teórico de lo que hoy se reconoce como CSS. Señala, además, que el inicio formal de este tipo de cooperación se remonta a los años 40 con la creación de la Liga Árabe, constituida por siete países en desarrollo del Medio Oriente.

Tal como lo menciona Tassara y Prandi (2016) a partir de los años 90, se han empezado a difundir también formas de CSS financiadas por donantes del Norte, como el caso de la Unión Europea con los programas regionales con ALC. Por ejemplo: URB-AL, Alfa, EUROsociAL, entre otros.

\section{Metodología}

A continuación, se realizó la comparación de dos procesos de $\mathrm{Cl}$ ya que, siguiendo a Sartori (2011), la comparación permite hacer un proceso de control de las generalizaciones con el fin de identificar que es consistente en ambos escenarios y que no. (p. 278) Determinando qué elementos son constantes en los procesos de $\mathrm{Cl}$ que desarrolla el SENA, y cuáles se manifiestan de una manera disímil. Y en segunda instancia, la comparación determinará si efectivamente los procesos de cooperación internacional se enmarcan en las categorías de CSS y CNS o si pueden clasificarse 
o complementarse con otras modalidades, como la cooperación técnica o la cooperación descentralizada.

Los dos instrumentos de análisis utilizados fueron el análisis cuantitativo y descriptivo de las dos experiencias. Para lo cual se tomaron las cifras de los resultados obtenidos en cada una de estas: las frecuencias de las áreas de actuación, evolución temporal de proyectos y acciones y sectores de actuación, tomando por una parte, información principalmente de la base de datos de Secretaría General Iberoamericana (SEGIB) y la Agencia Presidencial de Cooperación Internacional-Colombia (APC-Colombia), y por la otro, se realizó un análisis a las entrevistas dirigidas a actores clave que trabajan al interior del SENA en este tipo de proceso.

El estudio es de carácter transversal descriptivo, en la medida que el proceso de recolección de información permitirá analizar las variables relacionadas con las actividades de $\mathrm{Cl}$ del SENA con la información disponible para al año de aplicación del estudio. En cuanto a las experiencias, se seleccionaron dos casos emblemáticos de $\mathrm{Cl}$ realizados en los últimos años con entidades de otros países. Particularmente, se tomaron los casos de las agencias Agencia de Cooperación Internacional para el Desarrollo de Israel (Mashav) y el Centro de Cooperación Internacional para el Desarrollo de la Agricultura de Israel (Cinadco), como CNS; y el de la entidad Servicio Nacional de Aprendizaje Industrial (SENAI) en Brasil, como CSS. La información se organizó por categorías permitiendo tener de manera cercana los elementos y condiciones de actuación de la $\mathrm{Cl}$ y el papel del SENA.

En lo que respecta a las entrevistas, se realizó un muestreo no probabilístico, particularmente dirigido a personas claves sobre el proceso de $\mathrm{Cl}$ tanto en el SENA como la APC. En total se realizaron 3 entrevistas en profundidad enfocadas en indagar espe- cialmente como los actores visionan la CSS. Las entrevistas son el medio más relevante y primario de recolección de la información debido al vacío existente a nivel teórico, por lo que se pretendió que no solo aporten información para la investigación sino en general para la construcción de una teoría más sólida sobre la CSS.

Para poder realizar la comparación, se diseñaron 3 categorías de análisis principales, basadas en el concepto de "Proceso de Cooperación internacional institucional" que se han planteado para efectos del presente estudio, y que han servido de guía para la creación de las preguntas aplicadas en las entrevistas. Así como para contrastar la información recolectada sobre los resultados de las experiencias de $\mathrm{Cl}$ a analizar. Las categorías son:

1. Primero, fortaleza institucional, la cual hace referencia a las características que permiten establecer proceso de cooperación sólidos o débiles

2. Segundo, capacidad de gestión de procesos, es decir, en qué medida la institución tiene la estructura necesaria para activar los procesos de cooperación internacional

3. Y tercero, visión solidaria, la institución tiene una proyección interna de continuar aumentando, disminuyendo o mantener igual número de procesos de cooperación internacional.

Finalmente, se tomó la información de las entrevistas y se contrastó con la teoría y la información recolectada, inicialmente, de las entidades que participaron en los procesos.

\section{Orígenes del Servicio Nacional de Aprendizaje (SENA) \\ El Servicio Nacional de Aprendizaje (SENA) surge como un proyecto de Rodolfo Martí- nez Tono, fundador de la institución quien}


inspirado por el SENAl', institución brasilera le propone la idea al ex Ministro de Trabajo señor Raimundo Emiliani Román. Posterior a esto, el ex Ministro Emiliani Román, movido por la idea del sr. Martínez Tono, logra la aprobación por parte de la entonces Junta militar que gobernaba el país y se crea el SENA mediante decreto-Ley 118, del 21 de junio de $1957^{2}$. A partir de entonces la entidad comenzó a crecer aceleradamente, por el gran vacío que tenía el país en formación técnica para las empresas ${ }^{3}$. Eso generó una necesidad de fortalecer la entidad, especialmente a sus instructores, por lo que se empiezan a realizar distintos convenios con otros países durante la década de los 60 , como Brasil y Francia, o con entidades multilaterales como la Organización Internacional del Trabajo (OIT). Luego, su crecimiento en la década de los 80 obligó a hacer una gran reestructuración interna a través de la Ley 119 de 1994. Lo que permitió ampliar la oferta de cursos y programas a todas las áreas de la economía nacional. Por lo que hoy día llega casi a todos los municipios de Colombia y posee alianzas con gran parte del sector productivo en todos los campos.

\section{Contexto colombiano de la $\mathrm{Cl}$ en el} ámbito de la formación técnica y tecnológica realizado por el SENA

Dentro del campo de la educación se identifican dos macro categorías como lo son la educación escolar que comprende primaria y secundaria y la formación profesional que se divide en pregrados y postgrados. En

\footnotetext{
' Esta información tiene como fuente principal la página web del periódico El Espectador, uno de los más antiguos de Colombia y la página web oficial del SENA (SENA, 2015). https://www.elespectador.com/noticias/ educacion/fallecio-el-fundador-del-sena-rodolfo-martinez-tono-articulo-563794

${ }_{2}^{2}$ Página web SENA. http://biblioteca.sena.edu.co/ exlibris/aleph/u21_1/alephe/www_f_spa/icon/sena20/ historico/decreto.html\#seccion2

${ }^{3}$ Ministerio de Educación Nacional de Colombia. https://www.mineducacion.gov.co/cvn/1665/w3-article-307852.html
}

la segunda categoría se incluye también la formación técnica y tecnológica. El SENA es la entidad adscrita al Ministerio del Trabajo que utiliza el Estado colombiano para brindar formación especializada gratuita, invirtiendo en la creación de capital humano y generación de oportunidades de acceso al mercado laboral en actividades productivas que contribuyan al desarrollo social, económico y tecnológico del país.

Los pilares fundamentales del SENA recalcados en su misión y visión son: formación, empleo, productividad y desarrollo. Estos son igualmente aplicables en materia de convenios internacionales, tales como las triangulaciones, las comisiones mixtas de vecindad, la asistencia técnica y por supuesto en la Cooperación Sur-Sur. Teniendo en cuenta que la educación, la ciencia y la transferencia de tecnología son primordiales en el marco de los procesos de desarrollo de un país que, en el caso del SENA, se encuentra articulado a la educación superior técnica por su reconocida experticia internacional, presentadas a través de puntuales necesidades de la población, del aparato productivo y, en asuntos internacionales, de los países participantes en materia de convenios.

Adicional a esto el SENA, también sirve de puente con los sectores productivos locales al tener contacto directo con las empresas. Las necesidades de dicho sector son la principal fuente de justificación de las acciones del SENA y por supuesto la $\mathrm{Cl}$ no es la excepción. Con la firma de varios tratados de libre comercio por el gobierno colombiano, así como la apertura general a nuevos mercados más exigentes en temas de calidad y de precio, las empresas se han visto en la necesidad de buscar nuevos conocimientos más especializados. Tales conocimientos se encuentran en otros países y es entonces cuando los procesos de internacionalización empiezan a volverse una prioridad. 
EI SENA, como columna vertebral de la formación técnica y tecnológica en Colombia, le aportó al país, en 2008, cerca de 250.000 cupos para la formación de técnicos profesionales y tecnólogos, en áreas y especialidades requeridas por los sectores productivos del país. Aumentando en casi un $70 \%$ las matrículas para el 2014 (MEN, 2015) con un resultado de 399.597 matrículas ocupando el $60.2 \%$ de la formación para el trabajo en Colombia frente a 85 instituciones de formación tecnológica y técnica en los sectores públicos y privados.

Las intervenciones del SENA en el plano internacional se dan a partir de su misión institucional, operador por así decirlo, de la función que le corresponde al Estado colombiano en la inversión dentro de los planes y procesos de desarrollo social y técnico de los trabajadores, ofreciéndoles la formación profesional integral, incorporando estos contingentes en las actividades productivas que a su vez redunden el desarrollo económico, social y técnico del país. Puede apreciarse que su fundamento esencial es la formación en actividades productivas dentro de las competencias constitucionales de desarrollo del estado social de derecho.

En el contexto de alianzas para el desarrollo, Colombia ha logrado acumular un significativo caudal de experiencia y reconocimiento. De un perfil tradicional como receptor de ayuda, el país ha pasado a liderar estrategias, programas, proyectos $y$ acciones que consolidan su relevancia en el escenario de la cooperación internacional. Esos avances también se reflejan en el nivel de gestión de la cooperación colombiana, afianzada actualmente en el estándar institucional y transversalizada en múltiples instancias estratégicas. Cabe destacar que la CSS "ha sido incluida como uno de los siete desafíos y uno de los objetivos estratégicos de la cooperación en Colombia" (Nivia, 2013, p. 117). De ese modo, la Estrategia Nacio- nal de Cooperación Internacional-ENCI 2012-2014, de la APC, estableció las áreas de oferta y demanda de CSS colombiana. A partir de ahí se ha pretendido contribuir al desarrollo de capacidades, ampliando notablemente los temas de cooperación que por años estuvieron limitados a aspectos de seguridad.

Si bien el SENA se encarga de formar y certificar en distintas áreas técnicas y tecnológicas a los habitantes del territorio colombiano con la finalidad de capacitarlos para conseguir un trabajo y así aumentar los índices de empleabilidad del país, también es la institución insignia utilizada por la APC para llevar a cabo CSS. EI SENA recibe solicitudes o propuestas de cooperación por medio de dos canales. Por una parte, algunas llegan indirectamente por medio de la APC Colombia y otras directamente presentadas a la Oficina de relaciones internacionales de la entidad.

\section{Oficina de relaciones internacionales del SENA}

Es la dependencia encargada, dentro del organigrama de la institución, de fomentar y promover los convenios de acuerdo a las directrices de su misión y de la junta directiva compuesta por representantes del Ministro de Trabajo, Educación, Comercio, Asociación Nacional de Industriales, Federación Nacional de Comerciantes, Sociedad de Agricultores de Colombia, Asociación Colombiana de Pequeños Industriales (ACOPI), Central Unitaria de Trabajadores, Confederación General de Trabajadores, Asociación Nacional de Usuarios Campesinos, Colciencias y las Cooperativas de Colombia. La labor de la oficina de relaciones internacionales del SENA es la transferencia de conocimientos a través de alianzas con socios estratégicos que mejoren la calidad de la educación impartida en los centros de formación y en consecuencia la transfiera tecnología. Lo logra a través de la 
articulación regional, promoviendo la participación del SENA en eventos y foros internacionales, gestionando acciones concretas para conseguir la movilidad internacional de sus integrantes $\mathrm{y}$, sobre todo, manteniendo óptimas relaciones con diversos organismos internacionales.

El responsable de las operaciones internacionales del SENA es un coordinador de un grupo con esa misma denominación que responde a la dirección general del ente educativo. Se inicia con la identificación del socio cooperante y finaliza tras asegurarse que todo lo propuesto en el convenio se cumpla. El escritorio es la instancia del grupo de relaciones internacionales encargada de generar acuerdos, convenios, memorandos de entendimiento, actas de intención y otros documentos similares. El asesor es la persona encargada de la gestión de alianzas y proyectos internacionales para fortalecer las áreas de formación profesional, la innovación y el desarrollo tecnológico, mesas sectoriales y todo lo concerniente a las metodologías sobre formación profesional. Todos estos procesos son soportados por los documentos RECC-PL-004, Ley 80 de 1993, Ley 1150 de 2007, Decreto 734 del 2012, Acuerdo 016 del SENA y la Resolución 122 del 6 de febrero de 2012.

En su marco general, el SENA establece líneas de cooperación directa con instituciones de formación profesional, centros de desarrollo tecnológico, gobiernos, universidades, (Agudelo, 2014) entidades multilaterales, agencias de cooperación, organismos no gubernamentales tanto públicos como privados las cuales quedan plasmadas en acuerdos, contratos, convenios, actas de intención y proyectos para el fortalecimiento tecnológico. La idea central es establecer contacto con un posible socio cooperante. Se identifica plenamente y desde esa perspectiva surge el interés de oportunidades. La iniciativa puede partir del SENA, a nivel interno, de la Agencia Presidencial de Cooperación Internacional de Colombia, del Ministerio de Relaciones Exteriores analizando, ante todo, que la relación planteada sea de mutuo beneficio.

De no existir este requisito, se suspende la invitación o el posible convenio con el socio cooperante. Si el concepto es favorable, se redacta un estudio denominado "Estudio previo de conveniencia" por parte del asesor asignado al grupo que debe servir de insumo al convenio marco. Pasada esta etapa del proceso, se le solicita al socio cooperante la documentación que sirve de insumo para la formulación del respectivo convenio por parte de la Dirección general. Con los requisitos documentales y el estudio previo se presenta el respectivo convenio, memorando de entendimiento, acuerdo o el nombre que se le otorgue con los cronogramas precisos de ejecución y los correspondientes recursos económicos.

Pasado esta etapa, se remite el proceso para la gestión de contratación con todos los diversos trámites que dé lugar, incorporando recursos. Una vez que estos se encuentren disponibles, se establecen los lineamientos en la sede o centro de formación en donde se implantará el convenio con sus actividades, acompañado por un asesor nombrado por la Coordinación de relaciones internacionales y de cooperación. Se mantiene sobre el proyecto un continuo seguimiento, estableciendo que se cumplan los objetivos, el cronograma planteado con la ejecución de los recursos con una memoria de las actividades realizadas que se plasma en informes periódicos.

Al final, se realiza un completo informe por parte del supervisor del convenio o proyecto en que se detallan los logros, actividades, objetivos alcanzados, ejecución total de recursos y cronogramas cumplidos. Este informe se remite al proceso de gestión y contratación para que diseñen el acta de liquidación del proyecto o convenio. 
8. Análisis las experiencias de cooperación internacional del SENA: casos de Brasil e Israel

A continuación, se presentan dos casos puntuales en los que el SENA de Colombia participó en procesos de cooperación con instituciones de Brasil e Israel con cada uno de estos la entidad actúa como organismo receptor en el modelo de la cooperación. A nivel general, el propósito de los dos casos presentados a continuación es la búsqueda de mejoras en procesos internos de Colombia, tomando como ejemplo los casos de éxito presentados en estos países, a fin de que la región beneficiada, pueda poner en práctica técnicas de mejora, en especial implementación de nuevas técnicas y tecnologías, que permitan hacer de los sectores económicos implicados, más competitivos y eficientes en sus actividades productivas.

El socio cooperante en este caso es el Estado de Israel y dos de sus agencias gubernamentales: Mashav, que es la Agencia para la Cooperación Internacional de ese país, creado en 1958 como una división del Ministerio de Relaciones Exteriores, planificando e implementando programas de cooperación en 140 países; y Cinadco, Centro de Cooperación Internacional del Desarrollo Agrícola, que hace parte del Ministerio de Agricultura y que es responsable de encaminar programas relacionados con la producción intensiva y el desarrollo agropecuario sostenible. En este caso, el SENA actúa como agente receptor de la cooperación, al beneficiarse de la experiencia de las instituciones mencionadas en Israel.

Los beneficios de esta cooperación se ven potencializados por la experiencia que tiene el país emisor en este caso. A manera de contexto, el sector lácteo de Israel suple el $80 \%$ de la demanda interna y el resto se exporta, la producción anual es de 1.3 billones de litros. Por otra parte, la valoración total del negocio es de $\$ 2.6$ billones de dóla- res (The Dairy Industry, 2012). Esto ha favorecido el hecho de que la industria cuenta con una gran variedad de productos suplida por las 940 haciendas o fincas con reses que tienen en gran parte un cruce genético de la raza Holstein. Como aporte legislativo, el Parlamento israelí -Knesset- emitió en el 2013 una Ley sobre la leche.

Por otra parte, el sistema agrícola de Israel es intensivo, y particularmente en el sector lechero convergen científicos, universidades e industrias relacionadas en donde laboran 60.000 personas. Su sistema de producción es en las granjas Kibbutz y en el Mashav. La estructura de la industria lechera está compuesta de una asamblea general, una mesa de directivos, gerente general, controlados por un auditor. Este sector administrativo controla los departamentos de control de exportación, calidad, innovación y salud, dirección científica, sistemas, finanzas, planeación y administración y mercado (The Dairy Industry, 2012).

En Israel, y esto es importante, el Estado es el propietario de la tierra. La granja comunal Kibbutz comparte propiedad de los medios de producción con vinculación activa en la industria procesadora de lácteos con un $63 \%$ de la producción nacional. El Moshaw, con $37 \%$ de la producción, son granjas de propiedad familiar o individual.

Es importante destacar, que Israel tiene una gran dificultad para acceder a recursos hídricos, lo que afecta directamente los procesos de alimentación y sanidad de los hatos. Adicional a esto, las tierras no son en general aptas para el pastoreo de ganados a los que se suma un largo período de verano anual de por lo menos 6 meses. Ello implica alimentación en forrajes pagando precios altos y de mediana calidad, a los que se suma mano de obra escasa y a un alto costo.

En cuanto a los problemas derivados de la escasez de tierra, proponen un alojamiento intensivo de 25 animales por metro 
cuadrado, su refrigeración durante los períodos cálidos del clima, tres ordeños diarios y la automatización de monitores del hato. Con la implementación de esos procesos se permite un abastecimiento del $87 \%$, incremento de consumo per cápita, crecimiento sostenido del $2 \%$ anual, constante mejoramiento en la calidad y cooperación láctea y su papel de exportador de tecnología del sector representada en una experiencia en sistemas de alimentación y ordeño de ganado computarizados, equipos de procesamiento de leche, consultorías y proyectos internacionales (Mendoza, 2012). Puede apreciarse la experiencia y calidad del socio cooperante en el proyecto Cooperación Norte-Sur en el ramo de lácteos.

\section{Producción de leche en condiciones intensivas en Israel}

Dentro de los planes de la $\mathrm{Cl}$ para la producción intensiva de lácteos en el departamento del Atlántico, el SENA envió a un curso sobre el tema al especialista Mario Mendoza. En ese sentido, su informe presentado puntualiza los procesos observados para que Israel lograra un gran avance en la industria lechera superando todos sus problemas y convirtiéndolos en procesos de crecimiento. En lo referente a la pérdida de leche, la producción subió del $10 \%$ al 30\%, incrementando las grasas y proteínas, las tasas de concepción, la eficiencia nutricional y una estrategia para reducir el estrés calórico, pues estudios demostraron que redundan en una mayor producción. Es importante anotar que en el campo académico hay permanente innovación tecnológica, investigación de usos con búsqueda de soluciones a problemas específicos.

Según Mendoza, dos son los puntos clave necesarios para aprender de la experiencia israelí. Uno de ellos es la alimentación del ganado, donde se descarta el pastoreo por la ausencia de campos para este fin.
En su reemplazo se le practica una ingesta de Ración Total Mezclada (RTM) a cada res de 20 kilogramos. Los alimentos se concentran y almacenan en silos, formados por forrajes toscos el cual el $80 \%$ es trigo. Fibra muy importante para rumiarya que ayudan a elevar las partículas adheridas, pues sin estas las bacterias no podrían degradar los alimentos. Si no hay rumia, no hay saliva y por ende buffer, señala el experto Mendoza. En cuanto a los granos aportados se tratan de concentrados, vitaminas y minerales suministrados por un asesor técnico.

En cuanto al clima y el estrés calórico, se encuentran relacionados con el diseño de las instalaciones en donde se encuentra el ganado previniendo la presencia de la luz solar directa, las sombras, el uso de la ventilación natural cruzada con una orientación óptima con una altura de la edificación mínima de 10 metros. Pasando al hato, se hace un enfriamiento directo sobre el mismo con el mojado o humectación de las reses, una ventilación forzada y un mojado con ventilación forzada simultánea. En cuanto al enfriamiento indirecto, se hace en túnel de enfriamiento, neblinas, el Low profile cross ventilation y el enfriamiento evaporativo.

La infraestructura de los hatos lecheros tiene un sistema de separación por áreas según la etapa fisiológica del animal, según el manejo de ordeño y por criterios sanitarios. Esas áreas en las instalaciones se encuentran distribuidas en vacas de ordeño, cría de reemplazos, pasillo central de alimentación para tránsito de vehículos y sala de ordeño. Sobre los servicios veterinarios, son prestadas por una sociedad de veterinarios, un centro de alimentación, la asociación de criadores, la compañía israelí de inseminación y reproducción y el servicio nacional para la calidad de la leche.

Por su parte, en Israel, según el informe de la misión del SENA en la que participó Mendoza, hay monitoreos constantes auto- 
matizados con mediciones de flujo en el equipo de ordeño con el flujo de la leche, la detección de mastitis, datos de composición de la leche, la medición de desplazamientos, la tasa ruminal y la actividad de la vaca y las tecnologías sobre estado nutricional de la res.

En cuanto al estrés calórico, el enfriamiento redujo el $40 \%$ de pérdida de leche por estas circunstancias, pues el calor; $y$ he allí la importancia de los hallazgos de los israelís en los hatos del departamento del Atlántico, disminuye actividades, la rumia, produce un incremento de consumo de agua, amontonamiento y permanencia de pie, buscan ventilación natural, bajan la concentración de grasas y proteínas, se incrementan las infecciones y se reduce la tasa de concepción.

Señala que Israel y sus hatos constituyen marcos importantes de referencia para la intensificación de los sistemas productivos de lácteos en el departamento del Atlántico. Que la observación de equipamientos y tecnologías crea un marco de debate y análisis sobre su posible aplicabilidad y que Israel presenta condiciones climáticas y de oferta alimenticia cuya experiencia bien puede ser utilizada.

Por último, Mendoza (2012, p. 21) indica: "El reconocimiento e identificación de variables de producción y desarrollo de lecherías intensificadas significa la posibilidad de incorporación al escenario del SENA de estrategias de alimentación en Ración Total Mezclada (RTM), manejo del estrés calórico, el reemplazo y crianza de terneras y el uso de herramientas de gestión y monitoreo".

Las cifras del departamento del Atlántico en producción lechera no son alentadoras. En el 2012, producía 159.523 litros al día en un promedio de 3.7 litros por vaca cuando la producción media nacional maneja promedios de 4.8 litros ubicándose en el puesto 12. Por ello el programa de desarrollo lechero busca el crecimiento del país a través de la apropiación de modelos tecnológicos internacionales que la conviertan en competitivas.

En este sentido, el objetivo del programa Megaleche es "el mejoramiento de la cadena productiva a través de incremento de los niveles de producción en las fincas de la región para garantizar la competitividad de la misma agregando mayores niveles de rentabilidad" (Baena, 2014).

El programa fue creado en 2010 por la empresa privada COA (Consultores Operadores Agroindustriales) con el apoyo del gobierno del departamento del Atlántico, el SENA, Israel Agency for Interactival Development, Mashav y Cinadco. Sus líneas básicas son especialización en el hato ganadero, introducción de ejemplares con potencial genético y la intensificación ganadera. Su implantación, en las fincas involucradas, mejoró la eficiencia productiva en un $35 \%$.

Las innovaciones tecnológicas propuestas en el campo de la Cooperación NorteSurfueron:

» Producción, manejo y conservación de forraje

» Control de alimentación del hatoCrianza intensiva de terneros

» Cestión integral de la empresa ganadera

»Salud, instalación de producción y equipamiento

» Calidad de la leche e Implementación de buenas prácticas ganaderas.

Los objetivos fueron:

» Alcanzar una mayor y más eficiente producción en el Atlántico

» Generar un proceso basado en técnicas de manejo y tecnologías aplicadas y adaptadas a las condiciones de la región con un enfoque de intensificación.

Según Weiner, Tamir, y Valverde (2011) los hallazgos reportados por la misión 
durante la visita a estas fincas representativas fueron los siguientes:

» La mayoría de las empresas ganaderas del Atlántico son de doble propósito, lo cual significa que la lechería especializada no existe

» Nutrición de hatos en sistemas pastoriles

» Pasturas: extensivo y rotacionallmplementación de la alimentación en forma fija y acorde con los niveles de producción no es común

» Producción de pastos frecuente

» La oferta de subproductos para usar como alimentación es reducida e inestable

» No existe conciencia de nutrición balanceada en período seco

» El destete de las novillas es tardío (4 a 10 meses).

10. Convenios de intercambio sectorial: Caso entre el SENA de Colombia y el SENAI de Brasil en la industria lechera antioqueña y el sector de cueros y marroquinería

EI SENA de Colombia firmó varios acuerdos con su similar de Brasil, el SENAI para desarrollar proyectos de Cooperación Sur-Sur en sectores como los cueros, marroquinería y procesamiento lácteos; este último en el departamento de Antioquia. SENAI es la sigla en portugués de Servicio Nacional de Aprendizaje Industrial fue creado en Brasil por el Decreto - Ley No 4.048 del 22/01/42. Su iniciación fue promovida por el sector industrial brasilero constituyéndose, en el transcurso del tiempo, en un polo nacional e internacional de generación y divulgación del conocimiento aplicado al sector del desarrollo industrial. Forma por tanto parte del gremio Sistema de la Confederación Nacional de la Industria - CNI. Apoya en los desarrollos de conocimiento de 28 áreas industriales a través de la formación del recurso humano y de la prestación de servicios al sector productivo con investigaciones aplicadas e información sobre innovaciones tecnológicas.

Se encuentra integrado por un Departamento Nacional y 27 regionales. Su visión es "Consolidarse como el líder nacional en educación profesional y tecnológica y ser reconocido como inductor de la innovación y de la transferencia de tecnologías para la Industria Brasilera, actuando como padrón internacional de excelencia" S(SENAI, párr., 2020, trad. El autor). Su misión "Promover la educación profesional y tecnológica, la innovación y la transferencia de tecnologías industriales, contribuyendo a elevar la competitividad de la industria brasilera" (SENAI, párr., 2020, trad. El autor).

Tiene un régimen de unidad normativa con descentralización ejecutiva. Los cambios en la conceptualización que sirven de base al sistema de enseñanza -aprendizaje de formación profesional, se dan en función de los cambios de paradigmas en el pensamiento del desarrollo industrial brasilero.

Frente a una dinámica constante de cambios del entorno, el SENAI busca mecanismo de planificación con sus ofertas educativas con los actores principales del sector: empresas, academias, gobierno y sindicatos. El SENAI definió como estrategia fundamental, la constitución de comités técnicos sectoriales. La labor de ellos es la identificación inmediata de las competencias profesionales que requieren los trabajadores y la industria para establecerlos, validarlos e incluso actualizarlos. Para estas funciones cuenta con tres observatorios en educación, tecnología y trabajo.

Los Comités Técnicos sectoriales del SENAI, a diferencia del SENA en Colombia, son coordinadas por funcionarios del SENAI, institución dependiente de la Confederación Nacional de Industria, la entidad gremial del sector en ese país, lográndose de esta manera mayores niveles de articu- 
lación. El Convenio \#00280 de 2011 suscrito entre el SENA de Colombia y el SENAI de Brasil tiene como objetivo general contribuir a la promoción y el desarrollo de la capacitación de recursos humanos, promoción y el intercambio de transferencia de conocimientos y tecnologías y el intercambio de materiales bibliográfico, audiovisual y didáctico de interés. Un convenio marco en sus objetivos generales que se sintetiza en el "fortalecimiento de los centros de formación a través de la transferencia de conocimientos y la modernización tecnológicas con entidades internacionales" (Convenio 00280 /2011). Los objetivos específicos del Convenio 00280 de 2011 son los siguientes: consolidar un plan de trabajo de talla mundial para el sector de textil, confección, diseño, moda y cuero, actualizar los instructores, modernizar los ambientes de formación y producción, actualizar y desarrollar programas de formación y estrategias metodológicas.

Al final, la obligación del SENAI es trasladar a Colombia a 3 expertos en área textil, diseño, cuero, calzado y marroquinería, entregando un diagnóstico del sector con una correspondiente propuesta de modernización tecnológica. Estas propuestas se implementaron con el apoyo de la Cámara Colombiana de la Confección y el Cuero con un plan padrino vinculando a sectores afines de las ciudades de Bogotá, Medellín, Santandery Norte de Santander.

El convenio entre SENA y SENAI, Brasil de Cooperación Sur-Sur para la implementación de un modelo de prospección para el sector lácteo del departamento de Antioquia se desarrolló en el 2014. Dentro de ese proceso se identificó la cadena láctea en Colombia constituida por una serie de actores con roles bien definidos y diferenciados. Los proveedores de insumos son quienes suministran productos y servicios y lo conforman almacenes de productos agropecuarios que proveen fertilizantes, semillas, sal, melaza, maquinaria diversa y medicamentos. Los productores se encuentran dentro de la ganadería especializada y la de pequeños hatos. Los centros de acopio, otro importante eslabón, es el lugar donde se concentran la recolección de leche de los productores agrupados en cooperativas, acopio formal e informal. Luego sigue la industria, donde se modifica o transforma la leche, los comercializadores que llevan los productos al mayorista o minorista y los consumidores.

En el caso del departamento de Antioquia, es el mayor productor de leche a nivel nacional con un $19 \%$. La propuesta del modelo SENAI sobre este departamento en el sector lácteo tiene como objetivo "identificar las tecnologías emergentes del sector con un contexto específico de aplicación". Dentro de las recomendaciones, reunidos con expertos del sector lácteo en Antioquia se analizaron las prospectivas tecnológicas; o sea lo que sería necesario implementar en un determinado lapso en los procesos operacionales. También se incluyó la prospectiva del esquema de manejo de las organizaciones vinculadas, el impacto ocupacional que tienen, las posibles brechas educativas y sus dinámicas de superación.

Igual unas recomendaciones de acciones futuras, la actualización curricular para docentes y el ofrecimiento de servicios técnicos. Por último, un monitoreo general de los resultados esperados (SENA, 2014).

El modelo SENAI sigue prospectivas tecnológicas, impactos ocupacionales y recomendaciones para efectos de la formación de oficios y profesional. Obedece a un trabajo en equipo desarrollado con especialistas de las distintas universidades de Brasil, respondiendo a la siguiente pregunta: ¿Cuántos trabajadores se deberían formar en el futuro y con qué perfil profesional? Se hace con la finalidad de evitar posibles desequilibrios entre la oferta y la demanda formativa (OCDE - CEPAL, 
2013).

En un modelo que intenta, desde presupuestos técnicos y científicos, prever la necesidad de mano de obra futura calificada para la industria brasilera para que el SENAl, diseñe sus programas formativos. En el caso de estudio de Cooperación Sur-Sur se trata de aplicarlo en el sector lácteo antioqueño, el más importante del país, para realizar una prospección de necesidades puntuales.

El objetivo es investigar la identificación de las tecnologías emergentes de un sector y un contexto específico para su correspondiente aplicación. Se hace a través de la metodología Dolphi, en donde se entrevista a expertos y académicos del sector. Este sistema metodológico es usado desde los años 50 en Estados Unidos en procesos de investigación sobre las necesidades futuras cuyo objetivo es buscar un consenso por intermedio de cuestionamientos de estructura cualitativa y cuantitativa. La característica del método es el anonimato total de los participantes; con la notable excepción del investigador del procedimiento que maneja rondas de preguntas cuantas veces se requiera, con retroalimentación controlada sin ningún tipo de presión con las respuestas del grupo siempre en forma estadística.

Con base en la información anterior se determinan qué cambios pueden llegar a suceder en los perfiles ocupacionales de la industria láctea antioqueña en un mediano y largo plazo. Con ello se buscará orientar los nuevos programas del SENA o ajustar a nuevos requerimientos los ya existentes.

Los resultados del modelo se dan en prospectiva tecnológica, con tecnologías emergentes con probabilidades de difusión en los próximos 5010 años. También en análisis de ocupaciones emergentes, con los cambios ocupaciones por sector clasificándolos en ocupaciones emergentes o en evolución y en prospectivas organizacio- nales. De eso se trata del modelo de prospección SENAI, adaptado, por supuesto, a la industria láctea del departamento de Antioquia. En el caso de la industria láctea de Antioquia, la introducción de este modelo prospectivo dio unos importantes resultados en cuanto a necesidades específicas de formación profesional para que el SENA determine nuevas líneas de formación y pueda satisfacer la demanda de oficios de este sector en un lapso de 5 a 10 años de horizonte.

\section{Análisis de la información}

Dentro del campo teórico no se encontró un concepto que permitiera describir plenamente el fenómeno encontrado en Colombia, y teniendo como base otras definiciones, se plantea el concepto de "Proceso de Cooperación Internacional Institucional", el cual se puede definir como: la capacidad de gestión en procesos institucionales para lograr una visión de solidaridad internacional. En otras palabras, se trata de cuando una institución del Estado posee relaciones con otros países o entidades foráneas y por ello se plantea unas metas, las cuales exigen la puesta en marcha de planes y el funcionamiento de una estructura al servicio de este propósito. Más adelante, se abordarán con mayor profundidad las categorías de análisis que se desprenden de este concepto propuesto.

El siguiente análisis se divide en dos partes. Primero, se comparará la información encontrada durante las experiencias, y luego se procederá con la información de las entrevistas. A partir, de las experiencias descritas, se encontrarán distintos matices en el desarrollo de cada una de ellas. A su vez se hallaron similitudes en:

» La implementación de un model

» Creación de un programa e

» Inclusión del gobierno local.

Por otro lado, se identificaron diferencias 
como que la experiencia con Brasil planteó una metodología y un plan de trabajo que parte de un objetivo mayor del SENAI, revisión del modelo a implementar, el programa desarrollado con Brasil se encuentra mucho más estructurado e implica un seguimiento constante al proceso, las propuestas de Israel implicaban la inversión de dinero a productores, mientras que con Brasil los recursos eran más reducidos y controlados, la experiencia brasilera apuntaba a prever un escenario futuro de necesidad de mayor recurso humano para la industria, pero sin mayores resultados a corto plazo. Por su parte, la experiencia con Israel se enfocó en aumentar sustancialmente la producción y logró hacerlo en un 35\%, y el SENA actúa como receptor en la experiencia de Israel, mientras que con Brasil hace intercambio de conocimiento.

Por otro lado, las entrevistas realizadas a los actores que participan en los procesos claves de $\mathrm{Cl}$ en el SENA y la APC-Colombia fueron realizadas con la guía de preguntas construidas a partir de las categorías plan-

teadas anteriormente, divididas así:

Tabla. 1. Operacionalización de las categorías

\begin{tabular}{|c|c|c|}
\hline Concepto & Categoría & Preguntas \\
\hline \multirow{9}{*}{$\begin{array}{l}\text { Proceso de } \\
\text { Cooperación } \\
\text { internacional } \\
\text { institucional }\end{array}$} & \multirow{3}{*}{$\begin{array}{l}\text { Fortaleza } \\
\text { institucional }\end{array}$} & $\begin{array}{l}\text { 4. ¿Qué fortalezas y debilidades identifica en los procesos de CSS } \\
\text { de la institución? }\end{array}$ \\
\hline & & 5. ¿Cómo cree usted que se puede mejorar esas debilidades? \\
\hline & & $\begin{array}{l}\text { 6. En su opinión ¿Con qué países es más fácil realizar CSS y por qué? } \\
\text { ¿Con cuáles es más difícil y por qué? }\end{array}$ \\
\hline & \multirow{3}{*}{$\begin{array}{l}\text { Capacidad } \\
\text { de gestión de } \\
\text { procesos }\end{array}$} & 2. ¿Quiénes han gestionado el proceso de CSS? \\
\hline & & $\begin{array}{l}\text { 7. ¿Por qué cree que la institución es una de las entidades públicas } \\
\text { con mayor liderazgo en CSS en Colombia? }\end{array}$ \\
\hline & & $\begin{array}{l}\text { 9. A partir de su experiencia en la institución ¿cuál es su percepción } \\
\text { sobre el esquema de CSS que presta la institución? }\end{array}$ \\
\hline & \multirow{3}{*}{ Visión solidaria } & 1. ¿Cuándo y cómo surgió el proceso de CSS en el SENA? \\
\hline & & $\begin{array}{l}\text { 8. De acuerdo con su experiencia ¿qué tendencia proyecta el } \\
\text { proceso de CSS de la institución? }\end{array}$ \\
\hline & & $\begin{array}{l}\text { 3. ¿Cuál es su percepción general sobre el proceso de CSS en el } \\
\text { SENA? }\end{array}$ \\
\hline
\end{tabular}

Fuente: Elaboración propia

Esto será la base para construir el siguiente análisis. A continuación, se describirán los hallazgos:

\section{Visión solidaria}

Se ha denominado como una de las categorías la visión que comparten los actores e instituciones de ayudarse mutuamente a través de iniciativas de $\mathrm{Cl}$. A la pregunta "¿Cuándo y cómo surgió el proceso de CSS en el SENA?", se encontró que los entrevis- tados tenían respuestas que coincidían. Durante gran parte de las respuestas señalaban a la Cancillería como quien dispone de las políticas para la CSS y a la APC-Colombia como quien se encarga de la parte técnica de los acuerdos. Es decir, no es un proceso exclusivo o aislado del SENA, por el contrario, es una construcción donde participan varias entidades.

Uno de los entrevistados señaló los 
momentos clave en la historia de la CSS:

En 1955- se inicia la cooperación técnica como política exterior en Colombia. En los 605 y 70 se crea la Cooperación Internacional como política de Estado. En los 80 s con Cooperación Técnica para el Desarrollo, gracias al desarrollo de la cooperación técnica se amplía el concepto de CSS se comienza a ver como donante: se crea un fondo de cooperación y asistencia técnica propio de Colombia. En el 2008, se celebran los 40 años de la Cooperación Internacional en Colombia. Se crean instituciones para organizar la CSS entrante como receptor. ${ }^{4}$
También, otro de los entrevistados indicó como "activo" el papel de oferente que tiene actualmente Colombia. Así mismo, explicó que existen 2 procesos posibles para que se desenvuelva la cooperación desde su óptica, primero indicó que:

"1. La cancillería o la APC recepcionan solicitudes de los países para CSS

2. Mesa de acercamiento para conocer la disponibilidad

3. EI SENA verifica y responde de acuerdo con su disponibilidad."

En segundo lugar, planteó el mecanismo que encontrarán sintetizado en la siguiente tabla:

Tabla 2.

Síntesis de un proceso de $\mathrm{Cl}$

PROCESO O MECANISMO

1. Comisión Mixta: Existe una comisión mixta compuesta por varias entidades, donde se dialoga en las áreas en que los países son fuertes. Estas son dispuestas por la cancillería.

\begin{tabular}{|c|c|}
\hline A. & B. Otra forma: \\
\hline $\begin{array}{l}\text { 2. Cancillería cita a la APC-Colombia y se } \\
\text { mira en qué áreas por realizar CSS. }\end{array}$ & 1. Solicitudes llegan de los países. \\
\hline $\begin{array}{l}\text { 3. Se reúne con las entidades que puedan } \\
\text { estar interesadas. }\end{array}$ & $\begin{array}{l}\text { 2. APC-Colombia mira de qué manera puede } \\
\text { direccionarlo a través de qué entidades. }\end{array}$ \\
\hline
\end{tabular}

Fuente: Elaborado a partir de la entrevista realizada al funcionario del SENA.

${ }^{4}$ Tomado de la entrevista realizada al funcionario de la Agencia Presidencial para la Cooperación.
${ }^{5}$ Tomado de la entrevista realizada al funcionario del SENA. 
Figura 1. Proceso de cooperación Sur-Sur

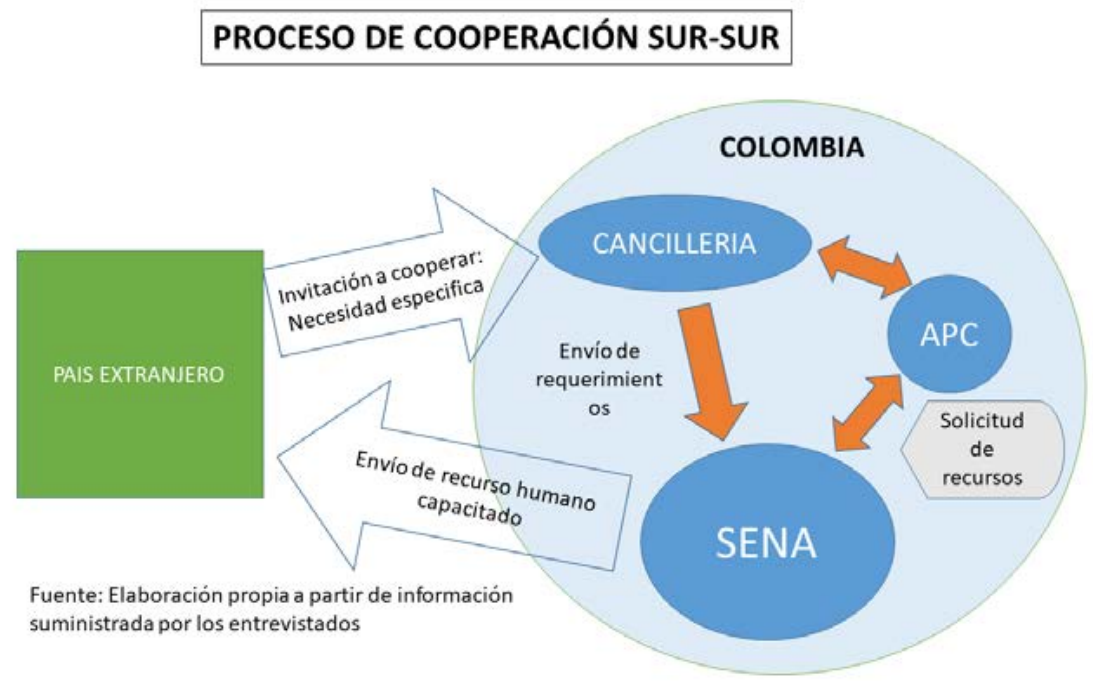

Fuente: Elaboración propia

Para la pregunta "8. De acuerdo con su experiencia ¿qué tendencia proyecta el proceso de CSS de la institución?" los entrevistados fueron claros y concisos, las palabras del entrevistado del SENA reflejan claramente la idea:

"Va a continuar dándose la CSS y se va a fortalecer"

En pocas palabras, el proceso es claro, consolidado y se desarrolla gracias al rol que juega cada uno de los actores. Entonces, podemos afirmar que si existe una Visión solidaria consolidada en el fenómeno de la $\mathrm{Cl}$ en Colombia.

\section{Fortaleza institucional}

Ahora bien, una de las categorías planteadas fue, lo que se ha denominado como la fortaleza institucional, que hace referencia a las características internas que permiten al SENA como institución generar procesos sólidos o débiles. Por ello, se le preguntó a los entrevistados "4. ¿Qué fortalezas y debilidades identifica en los procesos de CSS de la institución?", para el tema de las fortalezas la siguiente cita sintetiza la idea

${ }^{6}$ Tomado de la entrevista realizada al funcionario del SENA. general que compartieron los entrevistados:

"Fortaleza: el SENA está presto a apoyar CSS como oferente. Las calificaciones y comentarios han sido muy positivos.

Como receptores: no hemos tenido la experiencia de recepción sino más de oferentes.

Tratamos de mirar mecanismos de seguimiento que dependen de los compromisos adquiridos, pero NO es responsabilidad de Colombia darle seguimiento. La responsabilidad de la APC-Colombia es velar porque las actividades se cumplan.

EI SENA es un socio en la oferta de CSS. Ejemplo: Surinam - se realizó un intercambio en el que se certificaron bajo el programa de formador de formadores en minería. Valor agregado: el tema técnico impactó en el desarrollo con un proyecto con resultados y seguimiento de impacto."

Otro entrevistado anotó:

"La parte técnica se ha posicionado. Además, la capacidad y conocimientos de los instructores de la institución. La APC-Co-

${ }^{7}$ Tomado de la entrevista realizada al funcionario del SENA. 
lombia apoya el proceso de intercambio, $y$ hasta el momento no ha habido quejas. $\mathrm{O}$ por lo menos no que conozca."

En el tema de las debilidades, fueron aún más concisos y claros.

Aspectos a mejorar: Malas comunicaciones ocasionando reprocesos, falta de recursos y no hay traductores que manejen el lenguaje técnico requerido, el costo de esto lo asume la APC-Colombia ya que deben conseguir traductores simultáneos con conocimiento técnico, no hay contrapartida (no hay convenios donde se dé un 50/50), no hay reglamentación que regule este tipo de cooperación, la cooperación técnica es lo más importante, la plata es lo de menos. La CSS esta maniatada porque no hay un marco como el de los convenios de Cooperación Nacional y aunque no es común, pero hay poca disponibilidad de centros o de personal/fechas. ${ }^{9}$

Luego, se indagó sobre "5. ¿Cómo cree usted que se puede mejorar esas debilidades?" a lo que respondieron que: "Con la concentración de un convenio marco y además mayor personal."

De esta manera se pueden mejorar las falencias encontradas. En este orden de ideas, se les indagó por "3. ¿Cuál es su percepción general sobre el proceso de CSS en el SENA?", a lo que dieron palabras positivas: "La CSS es nueva, pero ha cogido fuerza, está organizado".

Otro entrevistado planteó que no solo se cumplían con los objetivos, sino que se iba "más allá": El proceso de CSS va en línea con la política exterior (POLEX) y está define las prioridades de la CSS. Institucionalidad actual: el MinExt tiene una oficina de CSS. La Cancillería establece estrategias bilaterales y regionales. Colombia va más allá y tiene

${ }^{8}$ Tomado de la entrevista realizada al funcionario del SENA.

${ }^{9}$ Tomado de la entrevista realizada al funcionario del SENA. estrategias regionales para evitar duplicar esfuerzos y recursos. El CSS es movilidad de conocimiento. No es intercambio de maquinaria o dotación de equipos hacia los países con los que se tiene estrategia. Lo que refleja un compromiso generalizado con los procesos, sin importar la entidad, aun conociendo las limitaciones.

\section{Capacidad de gestión de procesos}

Para esta tercera categoría, se les preguntó "2. ¿Quiénes han gestionado el proceso de CSS?" a lo que respondieron que la CanciIlería o Ministerio de Relaciones Exteriores, era quien lideraba los procesos de gestión con otros países.

También se les interrogó sobre "6. En su opinión ¿Con qué países es más fácil realizar CSS y por qué? ¿Con cuáles es más difícil y por qué?". No existe un consenso sobre los países, lo que si se mencionó fue a América Latina y el Caribe como los principales destinos de cooperación teniendo en cuanta que, "todo depende de la disponibilidad y de los recursos".

En concordancia con esto, la respuesta a la pregunta "7. ¿Por qué cree que el SENA es una de las entidades públicas con mayor liderazgo en CSS en Colombia?" fueron muy claro que el SENA debido a su amplia "capacidad institucional" y el conocimiento acumulado, era una entidad ideal para poder desarrollar estos programas de cooperación.

Finalmente, se requería conocer la percepción de manera general del esquema bajo el cual funciona actualmente el CSS, una de las respuestas:

"Considero que seguirá avanzando bilateralmente, pero apostándole a mecanismos regionales. Queremos y podemos, pero falta presupuesto".

En síntesis, una de las características encontradas es que existe una centralización, por parte de la Cancillería de gran parte, de la comunicación existente con 
los países que desean entablar proceso de cooperación con Colombia. Por esta razón, es que primero llegan las solicitudes a la Cancillería, quien luego las comunica a la APC y al SENA.

\section{Conclusiones}

Las acciones de los países en desarrollo deben poseer, en el campo de la cooperación internacional, un carácter eminentemente solidario. Se trata del surgimiento de una llamada "Conciencia del Sur" en donde los actores involucrados tienen la singularidad de la simetría. Precisamente el concepto de Cooperación Sur-Sur surge de objetivos políticos de integración y fortalecimiento de los países en vías de desarrollo, a través de una política de integración y fortalecimiento de coaliciones internacionales a través de la transferencia de conocimientos y tecnologías. En otras palabras, Colombia realiza Cooperación Sur-Sur en aras de desarrollarse a la par con países homólogos en el status de desarrollo tipificándose bajo lo que se conoce como Cooperación Técnica entre Países en Desarrollo (CTPD).

En Colombia, el trabajo de articulación en los procesos de cooperación está liderada por la Cancillería, quien genera los escenarios de oportunidad, pero manteniéndose en el escenario macro. Mientras que la APC-Colombia, es quien operativiza y enlaza al interior del país la dinámica de los convenios con los actores como gobiernos locales, entidades públicas u organizaciones privadas. Aun así, el SENA cobra un papel fundamental porque es quien ejecuta en gran medida parte de los procesos de cooperación, es decir, podemos denominar al SENA un motor de desarrollo para la cooperación internacional de Colombia.

La Cooperación Sur-Sur se encuentra ligado al concepto de solidaridad, lo más importante antes que competir es cooperar buscando enfoques de maximización de las ganancias. Esta cooperación es una de las formas del proceso histórico de las relaciones internacionales. Existen varios tipos; desde finanzas hasta transferencias de tecnologías, con asesorías de diversos tipos.

EI SENA articula su acción en la CSS con organismos similares en cuanto a objetivos y estructuras a través de una oficina de Relaciones Internacionales integrada por gremios de producción, sindicatos, estudiantes, cooperativas y representantes del gobierno central. Esta oficina es la que identifica a los posibles socios cooperantes y se encarga de generar acuerdos, convenios o actas de compromiso.

Los ejemplos presentados del SENA en su rol de motor de desarrollo en el marco de la CNS así lo muestran. Uno es el caso de Megaleche en el departamento del Atlántico, promovido por la Secretaría de Desarrollo Económico de la Cobernación del departamento del Atlántico en cooperación con agencias gubernamentales israelíes, país que pese a condiciones desventajosas para la industria láctea tiene altos índices de eficiencia y productividad, los cuales, tras estudiar hatos y fincas, señalaron importantes recomendaciones.

En el mismo sector de la industria láctea, pero ya en referencia territorial del departamento de Antioquia, el primero en Colombia en ese ramo de la economía, y en el marco de la CSS, se hizo un convenio con el SENAI de Brasil para aplicar su modelo de prospección usando el método Delphi. Igual la entidad brasileña similar al SENA, envió una serie de instructores para el estratégico sector de diseño, cuero y marroquinería.

Más allá de esto, encontramos profundas diferencias en el modus operandi de los procesos de CNS y CSS. En especial, la visión de paridad fue menor con Israel, pero con Brasil los recursos usados se enfocaron en el conocimiento que, con Brasil, permitió reducir ciertos costos. Aun así, los resultados a corto plazo del programa con Israel fueron contundentes y positivos en alcanzar sus objetivos. 
Si hay una similitud o tendencia es que en general, tanto en las experiencias analizadas como en las entrevistas, se mantenía una fuerte postura de planificación y organización del proceso. Se puede identificar una cierta experiencia institucional en llevar a cabo los procesos, poca improvisación e identificación de oportunidades, lo que revela una fortaleza institucional. Esto responde al asunto central del presente estudio.

En general las experiencias presentadas de $\mathrm{Cl}$, muestran la decisiva presencia del SENA como motor fundamental como oferente y receptor de CNSy CSS. La claridad en los procesos de implementación, estudio y capacitación tecnológica, y la sinergia con la APC-Colombia ratifican su función como pieza clave en el engranaje de la competitividad técnica internacional, la transferencia de conocimientos y el intercambio de tecnologías de Colombia.

\section{Referencias}

Agudelo, J. (2014). Marco Conceptual de la Cooperación Universitaria. Revista Internacional de Cooperación y Desarrollo., 1(1), 110-135. https://doi. org/10.21500/23825014.2257

Agudelo, J.(27 de diciembre del 2009). Cooperación Sur-Sur: Innovación y Transformación de la Cooperación Internacional. https://blogceiri.com.br/2009/12/27/ cooperacion-sur-\%E2\%80\%93-sur-innovacion-y-transformacion-en-la-cooperacion-internacional/

Ayllón, B., \& Ojeda, T. (2013). La cooperación sur-sur y triangular en América Latina. Catarata. https://www.academia. edu/4131253/La_Cooperaci\%C3\%B3n_ Sur_Sur_en_Am\%C3\%A9rica_Latina_ pol\%C3\%ADticas_afirmativas_y_ pr\% $3 \%$ A1cticas_transformadoras
Baena, A. (2014). Evaluación del incremento de la producción de leche cruda en las fincas intervenidas por el programa de desarrollo lechero "megaleche" en el departamento del atlántico. Facultad de Ingeniería de la Universidad del Atlántico, Colombia.

Cinadco. (2011). Centro de cooperación internacional para el desarrollo agrícola. Propuesta para el mejoramiento de la producción lechera en el departamento del Atlántico, región caribe Colombiana. Centro de cooperación internacional del ministerio de relaciones exteriores de Israel, Mashav.

Duarte, L., y González , C. (2014). Origen y evolución de la cooperación internacional para el desarrollo. Panorama, 8(15), 117-131.

Hynes, W., \& Scott, S. (2013). The Evolution of Official Development Assistance: Achievements, Criticisms and a Way Forward. OECD Development Co-operation Working Papers (12). http://dx.doi. org/10.1787/5k3v1dv3fo24-en

Lechini, G. (2009). La Cooperación Sur-Sur y la búsqueda de autonomía en América Latina ¿Mito o realidad? Revista Relaciones Internacionales (12), 55-81 https:// revistas.uam.es/relacionesinternacionales/article/view/4980

López, S. (2014). Cronología e historia de la Cooperación Sur-Sur. Un aporte desde Iberoamérica. https://cooperacionsursur. org/wp-content/uploads/2020/05/17DT05-Crono_SurSur_2014.pdf

Mendoza, M. (2012). Informe de comisión de estudios: Producción de leche en condiciones intensivas. Centro de cooperación internacional para el desarrollo agrícola.

OCDE-CEPAL. (2013). Perspectivas económicas de América Latina: políticas de PYMES para el cambio estructural. OCDE-CEPAL.

OIT. (2013). Modelo SENAI de Prospección, Brasil. https://www.oitcinterfor.org/instituci\%C3\%B3n-miembro/servicio-nacional-aprendizaje-industrial-senai 
OIT. (2013). La Cooperación Sur-Sury el Trabajo Decente: Buenas Prácticas. http://www. ilo.org/wcmsp5/groups/public/---dgreports/---exrel/documents/publication/ wcms_222162.pdf

Piketty, T. (2014). Capital in the twenty-first century. The Belknap press of Harvard University press.

Sartori, G. (2011). Como hacer ciencia política: Lógica, método y lenguaje en las ciencias sociales. Taurus.

SECIB. (2015). Informe de la Cooperación Sur-Sur en Iberoamérica. http://www. cooperacionsursur.org/images/informes/2015-informe-CSS-esp.pdf

SECIB. (2009). Informe de la cooperación Sur Sur en Iberoamérica 2009. https:// www.segib.org/?document=informe-de-la-cooperacion-sur-sur-en-iberoamerica-2009

SECIB. (2014). Resultados de la implementación del modelo SENAI de prospección Sector Lácteo Departamento de Antioquia (Colombia). http://www.cnl.org.co/wp-content/files/Propectiva_SENAI_Cadena_ lactea_Antioquia.pdf

Serviço Nacional de Aprendizagem Industrial (SENAI). (2020). UNEVOC Centre (National Body) since 2015. (I. Blanco, trad.).

Tassara, C. \& Prandi. (2016). Cooperación euro-latinoamericana y políticas públicas de cohesión social y lucha contra la pobreza. La experiencia del Programa EUROsociAL en Colombia. Opera, (18), (pp. 61-83). http://dx.doi. org/10.18601/16578651.n18.05

Tezanos, S., y Martínez, A. (2010). América Latina y El Caribe: Ayuda Oficial al Desarrollo en el punto de inflexión del milenio. Problemas del desarrollo, (41), 31-56. http://sci-hub.tw/http://www.scielo.org. $\mathrm{mx} /$ scielo.php?script=sci_arttext\&pi$d=$ S0301-70362010000300003\&In$\mathrm{g}=\mathrm{es} \& \mathrm{t} \operatorname{lng}=\mathrm{es}$.
Weiner, Tamir, y Valverde. Daniel Werner, CINADCO, Liron Tamir, IDB, Miguel Valverde Sánchez, COA (2011) Propuesta para el mejoramiento de la producción lechera en el departamento del atlántico región caribe colombiana.

Ley 80 de 1993. Por la cual se expide el Estatuto General de Contratación de la Administración Pública. 28 de octubre de 1993. D.O. No. 41.094

Ley 1150 de 2007. Por medio de la cual se introducen medidas para la eficiencia y la transparencia en la Ley 80 de 1993 y se dictan otras disposiciones generales sobre la contratación con Recursos Públicos. 16 de julio de 2007. D.O. No. 46.691

Decreto 734 del 2012 [Presidente De La República De Colombia] Por el cual se reglamenta el Estatuto Ceneral de Contratación de la Administración Pública y se dictan otras disposiciones. 13 de abril de 2012.

Acuerdo 16 de 2012. [Servicio Nacional De Aprendizaje] Por el cual se regula el Programa de Investigación, Desarrollo Tecnológico e Innovación y se subrogan los Acuerdos números 007 de 2006 y 004 de 2008. 29 de noviembre de 2012.

Resolución 122 de 2012. [Servicio Nacional De Aprendizaje] Por la cual se crean y reorganizan los Grupos Internos de Trabajo Permanente, adscritos a la Dirección de Promoción y Relaciones Corporativas de la Dirección Ceneral del Servicio Nacional de Aprendizaje SENA. 6 de febrero de 2012.

Decreto Legislativo del 4048 [Presidente De La República de Brasil] Por el cual se crea el Servicio Nacional de Formación de Industriales (SENAI). 22 de enero 1942. 